Não é de hoje que filmes comerciais são utilizados para promover produtos associando a narrativa dos seus enredos à imagem das marcas dos produtos que aparecem nesses filmes, haja vista o famoso Bonequinha de luxo, de 1961, e a marca Tiffany. 0 artigo Diálogos entre marcas de moda e narrativa cinematográfica em Anna Karenina, de autoria de Ana Paula Celso de Miranda e Amilcar Almeida Bezerra, aborda este assunto ao tratar da construção da identidade de marcas de bens de consumo presentes na narrativa do longa-metragem Anna Karenina e que provocam no espectador sentimentos de projeção por idealização via personagens.

0 texto chama a atenção do leitor para o curioso desejo "antropofágico" das pessoas de consumirem subjetividades, tema este bastante presente no cotidiano de consumo de praticamente todas as categorias de produtos de luxo. A subjetividade analisada encontra-se no fato de a trama se passar no século XIX e retratar cenas da vida de pessoas da nobreza em pleno século XXI.

Mas quem, mesmo que em fantasia, não gostaria de ser cortejada por um conde? Chanel e Dior, marcas que vestiram as personagens principais de Anna Karenina, sabem disso e investiram nessa ação de comunicação com o mercado exatamente com o intuito de reforçarem sua imagem de marcas de luxo mexendo com o imaginário das consumidoras loucas pela combinação de uma paixão perigosa envolvida em luxo.

E é sobre o estudo desse e de outros temas complexos, apaixonantes e contemporâneos, como a compreensão das comunidades de consumo e o estudo de estratégias, sobretudo de marcas como recursos de construção de significados entre empresas e sociedade, que se dedica o Grupo de Trabalho Consumo de Moda. Aos interessados em refletir e entender com maior profundidade assuntos ligados ao consumo de moda convidamos à leitura deste texto que foi escolhido como o melhor artigo do referido GT no ano de 2014.

Boa leitura a todos!

Olga Maria Coutinho Pépece

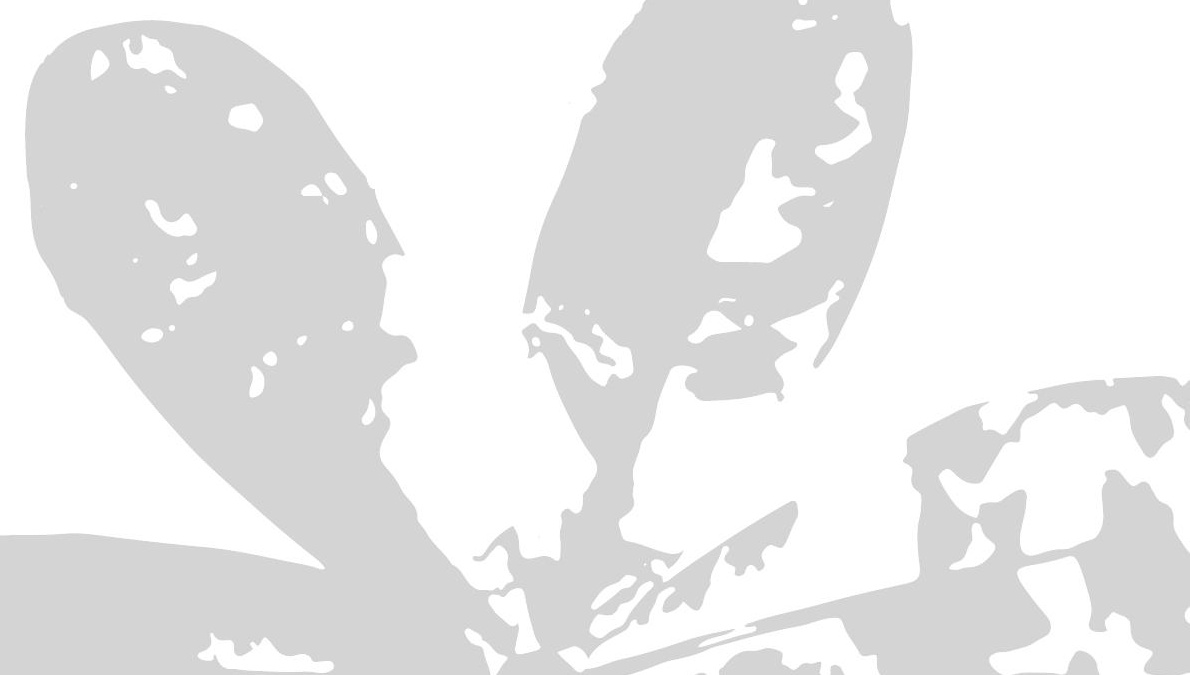


artigo $]$

[ ANA PAULA CELSO DE MIRANDA | AMILCAR ALMEIDA BEZERRA ]

Ana Paula Celso de Miranda é doutora pela FEA-USP. Professora das disciplinas Moda e Consumo e Moda e Cinema no curso de Design do Centro Acadêmico do Agreste (CAA) da Universidade Federal de Pernambuco (UFPE), onde é líder do Grupo de Estudos de Consumo de Moda (G-COMO). É diretora da Associação Brasileira de Estudos e Pesquisas em Moda (Abepem). Coautora de 46 livros de moda que você não pode deixar de ler, entre os quais Moda é comunicação: experiências, memórias, vínculos e autora de Consumo de moda: a relação pessoa-objeto. E-mail: anapaula.miranda@ufpe.br

Amilcar Almeida Bezerra é doutor em Comunicação pela Universidade Federal Fluminense (UFF), professor do curso de Design do Centro Acadêmico do Agreste (CAA) da Universidade Federal de Pernambuco (UFPE) e pesquisador do Grupo de Estudos em Consumo de Moda (G-COMO). Desenvolve pesquisas referentes a processos de produção, circulação e consumo de bens culturais, tendo participado de livros e filmes sobre o tema. É coordenador do curso de Comunicação Social do CAA-UFPE, que possui ênfase em Mídias Sociais e Produção Cultural. E-mail: amilcar.bezerra@gmail.com

\section{Diálogos entre marcas de moda e narrativa cinematográfica em Anna Karenina}

\section{Dialogues between fashion brands and the film narrative in Anna Karenina}

[resumo] Neste estudo, utilizamos o filme Anna Karenina, vencedor do Oscar de meIhor figurino em 2013, para analisar o vestuário de cena não apenas como elemento da narrativa, mas também como instância que possibilita agregar ao filme valores de marcas consagradas de bens de consumo, num processo de adensamento mútuo de sentidos entre marca e narrativa cinematográfica, com o objetivo de contribuir para a compreensão da dinâmica de consumo na atualidade.

\section{palavras-chave}

\section{moda; consumo; cinema; narrativa.}

[abstract] In this study, we used the film Anna Karenina, winner of the Oscar for best costume design in 2013, to analyze the scene clothing not only as an element of the film narrative, but also as an element that allows adding the values of acclaimed brands of consumer goods to the narrative. The aim of this work is to contribute to understand a sort of social dynamics of consumption in present days.

[keywords] fashion; consumption; cinema; narrative. 
0 figurino no cinema é composto por todas as roupas e os acessórios dos personagens, auxiliando a definir local, tempo e atmosfera da cena, bem como as características dos personagens (COSTA, 2002). 0 objetivo deste estudo é contribuir com a análise do figurino como elemento da narrativa no cinema, integrando, além dos aspectos do vestuário, o contexto narrativo no qual está inserido. Com isso, buscamos identificar algumas estratégias de mútua legitimação simbólica entre a narrativa cinematográfica e as narrativas de algumas marcas de moda expressas na concepção dos trajes de cena.

Os meios de comunicação de massa desempenham um papel cada vez mais relevante como fornecedores de matéria-prima simbólica para os múltiplos projetos individuais e coletivos de construção das identidades culturais na contemporaneidade. Por sua vez, o vestuário como traje de cena em produções ficcionais audiovisuais, de modo geral, é uma importante ferramenta de transmissão de valores e significados para o público que consome essas narrativas. Esse público, ao estabelecer relações de projeção por idealização com as personagens, tende a ancorar os significados associados à trama e à personagem no traje de cena, que acaba se legitimando como modelo estético a comunicar significados publicamente reconheciveis.

Moda e indumentária são fenômenos culturais e de comunicação [...] e algumas das maneiras pelas quais um grupo constrói e comunica sua identidade. [...] São comunicativas na medida em que constituem modos não verbais pelos quais se produzem e se trocam significados e valores. (BARNARD, 2003, p. 76)

\section{Por que Anna Karenina?}

Para entender os modelos idealizados representados pelos personagens do cinema que provocam o desejo "antropofágico" de consumir subjetividades, como num ritual mágico de transformação, escolhemos o filme Anna Karenina. Vencedora do Oscar de melhor figurino de 2013, a produção apresenta uma personagem central mitificada por várias versões dessa obra literária e utiliza, na construção do figurino, elementos estéticos associados a conhecidas marcas de moda, proporcionando um diálogo de contágio simbólico entre a personagem e a marca e vice-versa.

Adaptação do romance homônimo do escritor russo Leon Tolstói (1828-1910), originalmente publicado em 1878, o filme Anna Karenina, dirigido pelo inglês Joe Wright, foi o vencedor do Oscar de melhor figurino no ano de 2013. 0 enredo da película, ambientado na Rússia da década de 1870, tem como eixo central o conflituoso triângulo amoroso entre a protagonista Anna Karenina, o marido Alexei Karenin, um alto funcionário da burocracia russa, e o conde Alexei Vronsky, um jovem oficial da cavalaria. À medida que o caso extraconjugal de Karenina e Vronsky torna-se mais evidente aos olhos da sociedade da época, a protagonista passa a sofrer as consequências do rigoroso julgamento moral imposto pelo meio aristocrático ao qual também pertence.

Anna Karenina é o terceiro longa-metragem do diretor Joe Wright estrelado pela atriz Keira Knightley. Antes, haviam trabalhado juntos em Orgulho e preconceito (2005) e Desejo e reparação (2007), ambos adaptações de obras literárias. Foi também a terceira indicação de Jacqueline Durran ao Oscar de melhor figurino, tendo ganhado pela primeira vez a estatueta por seu trabalho no filme. Ela já havia sido agraciada com o BAFTA Awards, premiação da indústria cinematográfica britânica, pelo seu trabalho com o figurino do filme Vera Drake (2005), de Mike Leigh.

\section{Vestindo Anna Karenina}

Em seu clássico estudo sobre a reprodutividade técnica das obras de arte, Walter Benjamin (1936) já atentava para a natureza essencialmente "coletiva" do cinema. A magnitude da obra cinematográfica exige a mobilização de um grande volume de recursos materiais e simbólicos para sua realização e, consequentemente, uma difusão em massa para compensar os recursos mobilizados na produção. Assim, 0 
filme acaba sendo uma "criação da coletividade", na medida em que dela depende, necessariamente, para se viabilizar. Pressupondo, então, o filme como obra coletiva, entendemos que o conjunto de relações estabelecidas entre os indivíduos e as instituições que participaram de sua concepção e produção interage de forma intensa com o imaginário do público. Além disso, a numerosa equipe de produção de um filme acumula um considerável capital simbólico que corresponde a um complexo arcabouço técnico e teórico desenvolvido por meio da sistematização e da sedimentação de conhecimentos oriundos de diversas instituições do campo da arte e da mídia, dentre as quais as instituições de moda.

Neste artigo, observamos como parte desse capital simbólico é agenciado de modo a compor a construção da narrativa fílmica por meio da concepção do figurino da produção de Anna Karenina.

Conforme relata Jacqueline Durran, ela recebeu como briefing do diretor Joe Wright a missão de, com foco nas silhuetas típicas da época, simplificar a superfície da indumentária aristocrática da década de 1870 com inspiração na couture da década de 1950. Havia também a preocupação do diretor em dotar cada personagem de um figurino que representasse de forma particular não apenas características da personalidade, mas também o papel por ele exercido no desenvolvimento do enredo. A preocupação de situar a personalidade de Anna Karenina em contraste com os valores do seu meio social, por exemplo, levou Durran a materializar essa diferença em várias situações nas quais o figurino da protagonista se destaca de certa homogeneidade conscientemente aplicada a outros figurinos da cena.

Ciente do seu papel no conjunto da equipe, a figurinista define Joe Wright como um diretor com forte identidade visual e que costuma dar instruções precisas nesse aspecto da produção. Sua principal função como figurinista seria, então, concretizar a visão do diretor. Contudo, revela que várias decisões são tomadas em conjunto com Wright e Knightley, como, por exemplo, a opção pela parceria com a grife Chanel, que cedeu diversas joias para compor cenas do filme.

\section{Propondo uma perspectiva de análise}

Ao empreendermos a análise simbólica do figurino no filme Anna Karenina, partimos da premissa que a indumentária desempenha uma função significativa na construção da narrativa cinematográfica. Entendemos, portanto, que todas as escoIhas feitas no processo de produção do figurino, da criação à confecção, obedecem a propósitos específicos que residem na dimensão simbólica do material analisado. No caso do cinema, a dimensão simbólica do figurino se encontra, de variadas formas, subordinada à narrativa do filme, assim como todos os seus outros aspectos estéticos (cenários, sequências, planos etc.).

Como obra coletiva moderna por excelência (BENJAMIN, 1994), o cinema vem produzindo e reproduzindo uma mitologia contemporânea em profunda relação com o imaginário do público. Conforme professa Umberto Eco (1964), profissionais como cineastas, designers e publicitários produzem tendo como matéria-prima o imaginário popular, imagens míticas que vão se instalar na sensibilidade das massas'.

Produtores de obras coletivas como o cinema, portanto, mobilizam mitos contemporâneos num esquema de coparticipação com o público espectador/consumidor.

Assim, adotamos como pressuposto que, no planejamento do figurino, há uma preocupação dos produtores em agenciar conscientemente referências mitológicas midiaticamente consagradas para inseri-las como elementos visuais do figurino de maneira a fortalecer os laços simbólicos entre a estética das peças e os significados que habitam a narrativa em questão.

Por isso propomos uma análise semiológica de matriz barthesiana separada em três níveis: o denotativo, o conotativo e o mítico. Apoiamo-nos, ainda, na metodologia proposta por Gemma Penn, que aplica os conceitos de interpretação de signos a 
imagens paradas, na análise de figurino proposta por Maciel e Miranda (2009) e no modelo descritivo e interpretativo de planos e movimentos de câmera proposto por Jullier e Marie (2007).

Embora saibamos que, na prática, os processos de significação aconteçam simultaneamente em vários niveis de profundidade e consciência, consideramos pertinente, a título de análise, sistematizar a divisão acima proposta apenas com o propósito de tornar mais evidente a complexidade tanto dos processos de criação quanto de interpretação das imagens.

Para exemplificar nossa proposta de estudo, analisamos o vestuário da protagonista do filme na cena do baile, na qual se configura o romance que vai nortear toda a narrativa.

\section{Despindo Anna Karenina: a cena do baile}

Convidada pela jovem cunhada Kitty, Anna Karenina, acompanhada do irmão, comparece a um grande baile. Lá encontra, mais uma vez, o conde Vronsky, com quem já havia se deparado na estação de trem. 0 conde, até então provável pretendente de Kitty, não consegue esconder sua preferência por Karenina. A tensão entre as três personagens é o fio condutor da cena.

\section{Denotação}

Kitty usa um modelo branco com saia e ombros à mostra, aparentando um vestido de noiva. Anna Karenina usa um vestido preto, bastante decotado, e ostenta plumas, colar de diamantes em forma de flores e cabelo com um leve toque de desarrumação. Tem ombros à mostra, decote nas costas, saia no estilo 1870 atrás, mas com tule na frente e sem a cauda. Conde Vronsky usa traje branco assemelhado a uniforme militar.

Depois de um plano médio, em que a câmera frontal recua lentamente para acompanhar a entrada de Kitty no salão do baile, a câmera gira sobre o próprio eixo e desvela, num plano geral, o salão repleto de casais dançando harmonicamente em movimentos coreografados. As cores dos figurinos femininos, todos parecidos, variam em alguns tons pastel, à exceção das protagonistas da cena. Na sequência, predominam planos médios e closes, com a câmera acompanhando os movimentos da dança. Por instantes, enquanto Vronsky dança com Karenina, os demais casais ficam paralisados, estabelecendo um nítido contraste. No clímax da cena, Vronsky ergue Karenina num passo de dança e, quando ela volta a pisar no solo, o ambiente fica envolto na penumbra e uma luz branca ilumina sua dança com Vronsky no centro de um salão escuro e vazio.

\section{Conotação}

Nesta cena, o interesse mútuo despertado no encontro casual entre Karenina e Vronsky, que havia acontecido na estação, se transforma em paixão. Toda a cena e os movimentos traduzem sedução e carregam indícios das consequências que seus atos vão trazer para ela e para os outros. 0 figurino de Anna Karenina fala de sua personalidade e do seu papel na trama. Colocado num contraste em relação aos demais personagens, ele alude ao impacto que ela vai ter na vida dos que a cercam e na sua própria, no momento em que a paixão é revelada. Enquanto Vronsky e Karenina evoluem com seus passos de dança pelo salão, os figurantes aparecem paralisados, com vestimentas similares, para construir a impressão de completo alheamento do par central em relação ao ambiente da festa.

0 preto de Karenina já sugere o destino da personagem no desenrolar da narrativa a partir dessa cena-chave. Na cena em que ambos dançam sozinhos no salão, se estabelece o contraponto entre o branco (Vronsky) e o preto (Karenina).

0 visual de Anna Karenina tem seu apelo conotativo maximizado também em contraponto com o de Kitty. Luxo versus simplicidade; sedução versus inocência; experiência versus juventude. Reforça aqui o aspecto da construção do eu transferido para a narrativa do filme, no qual pessoas comparam a si próprias com outras, procurando por similaridades e diferenças para formar sua própria identidade (SPROLES, 1985). 
A cena se encerra com Karenina diante do espelho, no qual se vislumbra, e se ouve a chegada de um trem imaginário que prenuncia o seu destino trágico.

\section{Último ato: o nível mítico}

Percebemos que, no nível mítico, a narrativa das marcas de moda foi uma referência fundamental para a construção simbólica do figurino cinematográfico em Anna Karenina.

0 modelo de Anna Karenina usa referências do século XVIII, mas numa releitura modernizada, que a aproxima do público contemporâneo, para aludir à sofisticação e à feminilidade da personagem. 0 new look Dior é agenciado como manifesto do luxo e do poder de sedução, trazendo à tona o movimento e a sensualidade que um figurino histórico do século XVIII não poderia proporcionar. 0 hibrido entre essas duas referências alude a dois mitos que dialogam e reforçam suas identidades, criando possibilidades de vínculos com o espectador/consumidor. 0 objetivo da criação de figurino não seria, portanto, a veracidade histórica dos trajes, mas algo que produzisse um efeito de sentido funcional ao desenvolvimento da narrativa, em diálogo com os esquemas interpretativos de um potencial público consumidor da película.

0 colar utilizado por Anna Karenina nas duas cenas é da marca Chanel, construindo outro diálogo mítico no qual a sensualidade, a sofisticação e a força do universo feminino são reforçadas pela personagem, por seu figurino e pela marca como legitimadora do look enquanto expressão do eu no contexto da cena.

0 reforço das referências de Dior e Chanel é conscientemente agenciado para dotar de valores específicos associados às marcas o caráter da personagem por meio do figurino.

\section{Considerações finais}

Com o objetivo de identificar elementos comunicacionais do vestuário, este estudo propôs uma forma de ver e perceber a moda como elemento da narrativa cinematográfica. Encaramos o vestuário como uma narrativa dentro da narrativa fílmica, que serve de suporte para a construção de identidades coletivas de segmentos da audiência, ao passo que transfere para as marcas valores associados aos personagens.

A indústria cinematográfica pode ser considerada, hoje, uma instância fundamental de criação e disseminação de valores éticos e estéticos. Sua aproximação cada vez maior com o universo da moda apenas reforça esse lugar estratégico, ao mesmo tempo que fortalece a simbologia das marcas em questão. A marca representada pelo diretor Joe Wright e sua equipe de produção, consagrada pelo requinte visual e cenográfico de suas produções, bem como a persona feminina de Keira Knightley, que vem se consolidando como imagem mítica associada à conquista da autonomia feminina na busca pelo amor romântico, são elementos simbólicos que, por si só, já permitem estabelecer um diálogo harmonioso com as narrativas de marcas de moda agenciadas que, por sua vez, suplementam a construção simbólica da personagem.

Por outro lado, marcas contemporâneas utilizam o universo simbólico do cinema como ferramenta poderosa de atração sobre uma ou outra direção estética, gerando o que se chama de tendência. Produtos são providos de significado na sociedade; o estudo do simbólico reside em entender como as pessoas compõem o seu próprio conceito e consomem produtos que as identifiquem com a forma idealizada, atraídas por seus significados. 


\section{REFERÊNCIAS}

BENJAMIN, Walter. Obras escolhidas: magia e técnica, arte e política. São Paulo: Brasiliense, 1994.

BARNARD, Malcon. Moda e comunicação. Rio de Janeiro: Rocco, 2003.

COSTA, Francisco Araujo da. O figurino como elemento essencial da narrativa. Famecos: sessões do imaginário. Porto Alegre, n. 8, p. 38-41, ago. 2002.

DICHTER, Ernest. Why we dress the way we do. In: SOLOMON, Mlchael R. (Ed.). The psychology of fashion. Massachusetts: Lexington Books, 1985, p. 29-38.

DONDIS, Donis A. Sintaxe da linguagem visual. São Paulo: Martins Fontes, 1997.

DURRAN, Jacqueline. Meet the woman behind Keira Knightley's Anna Karenina costumes: Jacqueline Durran. The Fashion Spot. 14 nov. 2012. Entrevista a Jennifer Davidson. Disponivel em: <http://www. thefashionspot.com/runway-news/177335-meet-the-woman-behind-keira-knightlys-anna-kareninacostumes-jacqueline-durran/>. Acesso em: 16 dez. 2013.

. An interview with Oscar-winning costume designer Jacqueline Durran. Huffington Post. 26 fev. 2013. Entrevista a Mary Hall. Disponível em: <http://www.huffingtonpost.com/mary-hall/jacquelinedurran-best-costume-design-oscars_b_2762016.html>. Acesso em: 16 dez. 2013.

ECO, Umberto. Apocalípticos e integrados. São Paulo: Perspectiva, 2004.

JULLIER, Laurent; MARIE, Michel. Lendo as imagens do cinema. São Paulo: Senac, 2012.

KOURLAS, Gia. Making words dance on screen. The New York Times. Nova York, p. C1, 24 nov. 2012.

LÉVI-STRAUSS, C. 0 pensamento selvagem. São Paulo: USP,1970.

LIPOVETSKY, Gilles. O império do efêmero: a moda e o seu destino nas sociedades modernas. São Paulo: Companhia das Letras, 1989.

LURIE, Alison. A linguagem das roupas. Rio de Janeiro: Rocco, 1997.

MACIEL, E. J. C. ; MIRANDA, Ana Paula Celso de. DNA da imagem de moda. In: V COLÓOUIO NACIONAL DE MODA, 2009, Recife. Anais do V Colóquio Nacional de Moda, 2009.

PENN, Gemma. Análise semiótica de imagens paradas. In: BAUER, Martin; GASKELL, George. Pesquisa qualitativa com texto, imagem e som: um manual prático. Petrópolis: Vozes, 2002, p. 319-342.

SOLOMON, Michael R. Consumer behavior: buying, having, and being. Massachusetts: Prentice-Hall, Inc. New-Jersey. 1996.

SPROLES, George B. Behavioral science theories of fashion. In: SOLOMON, Mlchael R. (Ed.). The psychology of fashion. Massachusetts: Lexington Books, 1985, p. 55-70.

THOMPSON, C. J.; Caring consumers: gendered consumption meanings and the juggling lifestyle. Journal of Consumer Research. Vol. 22 March, 1996.

WRIGHT, Joe. Anna Karenina. [Filme]. Produção anglo-americana dirigida por Joe Wright. 129 min. color. son. 